\title{
PENGARUH BAK RESAPAN SERI TERHADAP PENURUNAN LIMPASAN PERMUKAAN
}

\author{
Briberliant Kurnia Saptaji Adinata'), Sobriyah ${ }^{2}$, Siti Qomariyah ${ }^{3)}$ \\ Mahasiswa Jurusan Teknik Sipil, Universitas Sebelas Maret \\ Pengajar Jurusan Teknik Sipil, Universitas Sebelas Maret \\ Jln. Ir. Sutami 36 A, Surakarta 57126 \\ e-mail : Briberliant@gmail.com
}

\begin{abstract}
Infiltration Tub is water infiltration facility which used to cope the flood by absorbing and infiltrating the water into the ground. The increasing ability of soil to absorb water can minimize the chances of surface water flow (surface runoff) in order to reduce the potential of flood. The research type was infiltration tub experiment which function is to reduce surface runoff. The research location was at Bapak. Sumarno's yard in Klodran, Karanganyar. This study performed was using 3 infiltration tubs with $50 \times 50 \times 50 \mathrm{~cm}$ volume. Infiltration Tub's side were closed using rebates concrete so that the water did not seep to the side. In tub infiltration influence of runoff, the results showed that the further and the more the tub is the more tub infiltration discharge not be reduced in saturated soil. In 30 minutes, surface runoff which can be reduced in Qinflow $0.202 \mathrm{l} / \mathrm{s}$ on dry soil was 100\% and on moist soil was 100\%, in Qinflow $0.3654 \mathrm{l} / \mathrm{s}$ on dry soil was 100\% and on moist soil was 100\% and in Qinflow $0.8178 \mathrm{l} / \mathrm{s}$ on dry soil was 84,36\% and on moist soil was 57,019\%. The number of infiltration tub was contributing on the reduction of surface runoff effect as long as the soil was saturated yet. In the water-saturated soil condition, the water absorption was inconsiderable. The result of this research matched with the coefficient permeability of soil from soil testing before. It was 3,1 × 10-7 cm/sec and 4,2 × 10-7 cm/ sec. The soil test was held in Alaska Laboratory, Jebres, Surakarta.
\end{abstract}

Keywords : Infiltration Tub, surface runoff

\begin{abstract}
Abstrak
Bak resapan adalah salah satu fasilitas resapan air yang digunakan untuk mengatasi banjir dengan cara menampung dan meresapankan air ke dalam tanah. Peningkatan kemampuan tanah dalam meresapkan air dapat memperkecil peluang terjadinya aliran air permukaan (surface runoff) sehingga dapat mengurangi potensi banjir. Seberapa besar penambahan resapan air oleh bak resapan belum diketahui sehingga menarik untuk diteliti. Jenis penelitian ini adalah eksperimental dengan pembuatan rangkaian seri bak resapan untuk mengurangi limpasan permukaan. Lokasi penelitian berada di depan teras Bpk. Sumarno di Klodran, Karanganyar. Penelitian ini dilakukan dengan menggunakan 3 buah bak resapan yang pada setiap bak resapan mempunyai dimensi 50 × 50 x $50 \mathrm{~cm}$. Dinding bak resapan ditutup menggunakan rabat beton agar air tidak meresap pada sekitar dinding bak resapan. Hasil penelitian menunjukkan bahwa pengaruh bak resapan terhadap limpasan permukaan ini adalah semakin jauh jarak dan banyak bak resapan maka semakin besar debit yang dapat direduksi selama tanah belum jenuh. Dalam waktu 30 menit limpasan permukaan yang dapat direduksi pada Qmasuk 0,202 liter/detik dengan kondisi tanah kering sebesar 100\% dan kondisi tanah lembab/basah sebesar 100\%. Pada Qmasuk 0,3654 liter/detik dengan kondisi tanah kering sebesar 100\% dan Qmasuk dan kondisi tanah lembab/basah sebesar 100\%. Pada Qmasuk 0,8178 liter/detik dengan kondisi tanah kering sebesar 84,36\% dan kondisi tanah lembab/basah sebesar 57,019\%. Jumlah bak resapan berpengaruh terhadap besar reduksi limpasan permukaan selama kondisi tanah belum jenuh. Pada kondisi tanah yang jenuh air yang meresap kecil. Hal ini sesuai dengan koefisien permeabilitas tanah di area penelitian sebesar 3,1 x $10^{-7}$ dan $4,2 \times 10^{-7} \mathrm{~cm} /$ detik yang dihasilkan dari uji tanah di Laboratorium Alaska, Jebres, Surakarta.
\end{abstract}

Kata kunci : Bak Resapan, Limpasan Permukaan.

\section{PENDAHULUAN}

Pola pengguaan lahan merupakan pencerminan dari kegiatan-kegiatan manusia yang ada di atasnya. Menurut FAO dalam Silwanus Matheus Talakua, (2016) bahwa 1/4\% tanah daratan dunia berupa daratan gersang, $11 \%$ tanah daratan berupa areal untuk ditanami/berisi tanaman $1 / 3 \%$ tanah didaratan ini ditempati oleh kota-kota, jalan, dan bangunan-bangunan lainnya. Kun Yulia Hidayanti (2009) menyatakan bahwa ketersediaan air tanah dalam di Kota Surakarta dalam rentang waktu tahun 2006 - 2012 turun drastis. Tahun 2006 di perkirakan volume air tanah masih sebesar 33 juta $\mathrm{m}^{3}$ sedangkan pada tahun 2012 volume air tanah hanya sebesar 21 juta $\mathrm{m}^{3}$. Tingkat kehilangan air tahun 2010 adalah sebesar 39,80\% atau diatas tingkat toleransi air sebesar 20\% seperti tertera pada Keputusan Menteri Dalam Negeri nomor 47 tahun 1999. Menurut Peraturan Menteri Negara Lingkungan Hidup Nomor : 12 Tahun 2009 tentang Pemanfaatan Air Hujan menimbang bahwa air hujan dapat dimanfaatkan sebagai imbuhan air 
tanah dan/atau dimanfaatkan secara langsung untuk mengatasi kekurangan air pada musim kemarau dan kelebihan air pada musim penghujan.

Padatnya bangunan di daerah perkotaan mengurangi luasan air untuk meresap sehingga meningkatkan debit puncak di hilir daerah tersebut. Kondisi ini disebabkan perubahan tata guna lahan dari areal resapan air yang menjadi kawasan pemukiman. Salah satu upaya yang bisa dilakukan untuk mengatasi masalah kekeringan dan kelebihan air adalah melakukan konservasi air tanah. Prinsip dasar konservasi air adalah mencegah atau meminimalkan air yang hilang sebagai aliran permukaan dan menyimpannya semaksimal mungkin ke dalam tubuh bumi. curah hujan yang berlebihan pada musim hujan tidak dibiarkan mengalir ke laut tetapi ditampung dalam suatu wadah yang memungkinkan air meresap ke dalam tanah (groundwater recharge) melalui pemanfaatan air hujan dengan cara membuat kolam pengumpul air hujan, sumur resapan dangkal, sumur resapan dalam dan lubang resapan biopori. Salah satu upaya yang bisa dilakukan untuk melakukan konservasi air tanah, mengatasi banjir dan kekeringan adalah bak resapan. Bak resapan merupakan inovasi lanjutan dari konsep sumur resapan. Sumur resapan adalah sumur atau lubang pada permukaan tanah yang dibuat untuk menampung air hujan agar dapat meresap kedalam tanah. Kelebihan dari bak resapan dibandingkan dengan sumur resapan adalah mudah dikerjakan karena dimensinya minimalis, perawatan sederhana, titik penyerapan lebih maksimal karena antar bak resapan saling terhubung, dapat ditutupi beton/aspal sehingga efisiensi lahan. Bak resapan dapat dibuat secara individu maupun kolektif. Manfaat yang dapat diperoleh dengan pembuatan bak resapan antara lain: meresapkan air lebih efektif dan efisien sehingga dapat mengurangi banjir, menambah cadangan air tanah, menjadi salah satu alternatif pengganti sistem drainase.

\section{DASAR TEORI}

\section{Tinjauan Pustaka}

Tri Yayuk Susana (2012) melakukan penelitian tentang pemanfaatan potensi air hujan dengan menggunakan bak/tangki dalam tanah dapat menghemat air PAM sebesar 65,41\% dari total kebutuhan air pertamanan. Ayu Wahyuningtyas dkk (2011) menyatakan bahwa pemodelan 903 sumur resapan di kota Malang dapat meresapkan air limpasan sebesar 0,62979 m3/detik, sehingga total debit yang diresapkan adalah sebesar 53,926 m3/detik. Debit air yang melimpas adalah sebesar $56,874 \mathrm{~m} 3 /$ detik dengan sisa debit yang melimpas di dalam saluran drainase adalah 2,947 m3/detik. Berdasarkan analisis yang dilakukan dapat disimpulkan bahwa sumur resapan efektif digunakan sebagai pengendali banjir. Dengan demikian, sumur resapan berguna pula untuk konservasi air tanah serta menekan laju erosi. Kusnaedi (2011) mengatakan bahwa keefektifan sumur resapan sangat tergantung pada volume dan jumlah sumur resapan.

\section{Kerangka Pikir}

Bak resapan merupakan inovasi lanjutan dari konsep sumur resapan. Prinsip kerja bak resapan sebenarnya hampir sama dengan prinsip kerja sumur resapan yaitu menyalurkan dan menampung air hujan kedalam lubang bawah tanah agar air dapat memiliki waktu tinggal dipermukaan tanah lebih lama sehingga sedikit demi sedikit air dapat meresap ke dalam tanah Namun, perbedaannya adalah titik penyerapannya, jumlah lubang, serta dimensinya. Konsep dasar dari bak resapan ialah memberikan kesempatan dan jalan pada air hujan yang jatuh di atap atau lahan yang kedap air untuk meresap kedalam tanah dengan cara menampung air tersebut pada suatu sistem resapan. Bak resapan merupakan penggabungan antar bak kosong yang saling terhubung satu dengan lain yang berada didalam tanah dengan kapasitas tampung yang cukup besar serta menekan pada jumlah area titik yang besar pula.

\section{Debit Aliran}

Debit aliran air adalah benyaknya volume zat cair yang melalui suatu penampang tiap satuan waktu. Satuan debit yaitu satuan volume persatuan waktu ( $\mathrm{m}^{3} /$ detik). Rumus debit adalah:

Debit $=\frac{\text { Volume Aliran }}{\text { Waktu Aliran }}$

\section{METODE PENELITIAN}

Penentuan Dimensi Bak Resapan 
Bak resapan merupakan terusan dari sumur resapan sehingga pedoman dalam penentuan dimensi bak resapan mengacu pada buku Sumur Resapan Untuk Pemukiman Perkotaan dan Pedesaan (Kusnaedi, 2011) yaitu dengan bentuk kotak dengan panjang $50 \mathrm{~cm}$, lebar $50 \mathrm{~cm}$, dan kedalaman 50-100 cm. Dalam penelitian ini digunanakan 3 buah bak resapan dengan ukuran masing-masing bak 50 x $50 \mathrm{~cm}$ yang saling terhubung dengan pipa berjarak dari tiap tepi $80-100 \mathrm{~cm}$. Lahan pada area bak resapan tertutup sebagian dengan rabat beton untuk mengetahui bahwa air yang meresap kedalam tanah berasal dari bak resapan. Gambar 3.21 Menunjukkan gambar tampak atas bak resapan serta dimensinya.

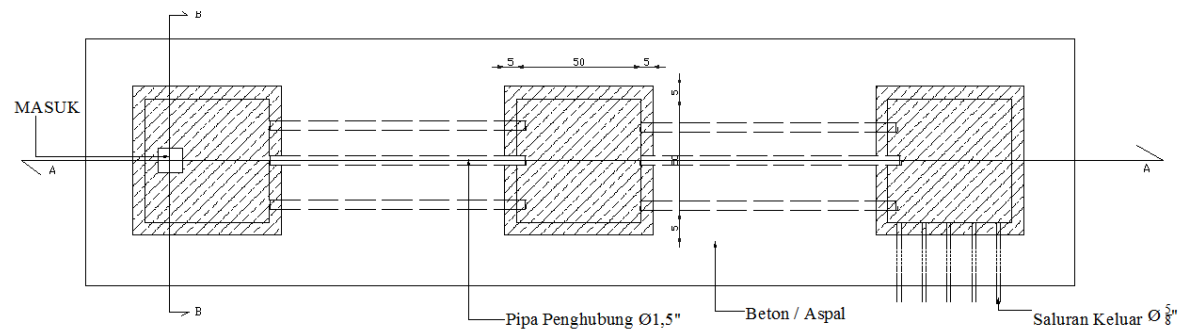

Gambar 1. Tampak Atas Penelitian Bak Resapan

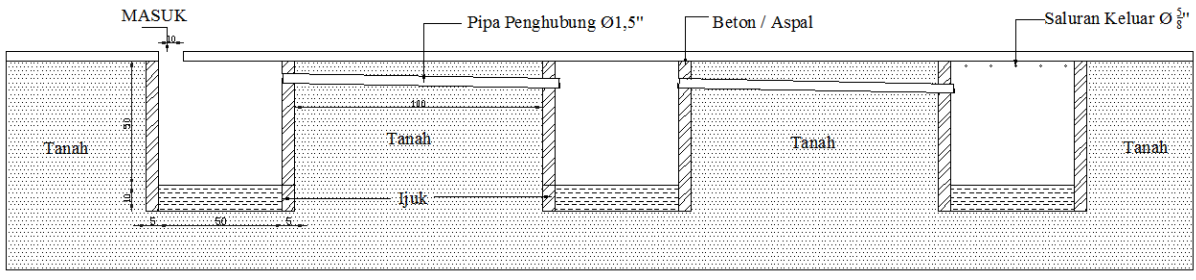

Gambar 2. Potongan A-A Bak Resapan

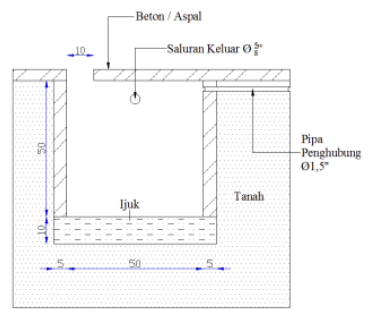

Gambar 3. Potongan B-B Bak Resapan

\section{HASIL DAN PEMBAHASAN}

\section{Pembuatan Bak Resapan}

Sebelum memulai penelitian, area penelitian terlebih dahulu dibuat. Pembuatan area penelitian meliputi:

1. Survey lokasi

2. Desain lahan

3. Pembersihan lahan

4. Pembuatan bak resapan

5. Penutupan permukaan bak resapan dengan rabat beton

6. Pemberian air

\section{Pelaksaan penelitian}

Penelitian ini dilakukan pada musim kemarau, sehingga debit yang semula direncanakan menggunakan air hujan menjadi menggunakan air dari keran. Untuk memendapatkan debit aliran air dibuat saluran pipa karet air sebanyak 3 buah menuju lubang pintu bak 1 . Sumber air yang digunakan untuk penelitian berasal dari reservoir dan pompa air yang berada pada wadah tong besi. Debit aliran diukur dengan cara selang air dialirkan pada wadah yang telah 
diketahui volume serta mencatat lama waktu air untuk memenuhi wadah tersebut yang selanjutnya dihitung debit aliran. Hasil pengukuran dan perhitungan didapatkan 3 debit yang berbeda (debit 0,202 liter/detik, debit 0,3654 liter/detik, 0,8178 liter/detik). Penelitian ini menggunakan 2 kondisi tanah, yakni kondisi tanah kering dan tanah lembab/basah. Kondisi tanah kering diperoleh dengan cara pengeringan tanah dari sinar matahari secara langsung selama 2-3 hari pada musim kemarau tanpa adanya tindakan pengairan air terhadap tanah sekitar, sedangkan pada kondisi tanah lembab/basah dilakukan dengan mengalirkan air kedalam lubang bak resapan dengan lama waktu pengairan minimal 3 jam hingga air menggenang cukup lama untuk terserap kedalam tanah kembali.

\section{Running Debit 0,202 liter/detik}

Tahap pertama yang dilakukan dalam percobaan kondisi tanah kering ini dengan mengalirkan air kedalam bak resapan-1. Lama pengairan selama 30 menit dengan mencatat ketinggian muka air pada bak resapan setiap 5 menit serta melakukan pencatatan waktu aliran air mulai masuk pada setiap bak resapan. Kondisi tanah kering dan lembab/basah mendapatkan penanganan yang sama dalam penelitian ini. Selanjutnya didapat data sebagai berikut:

Tabel 1 Debit masuk 0,202 liter/detik pada tanah kering

\begin{tabular}{ccccc}
\hline No. & Debit & Interval Waktu & Bak 3 \\
& & Bak 1 & Bak 2 & $00: 48: 26$ \\
\hline 1. & 0,202 liter/detik & $00: 00: 00$ & $00: 12: 55$ & \\
\hline
\end{tabular}

Tabel 2. Tinggi muka air tiap bak selama 30 menit pada debit 0,202 liter/detik pada tanah kering

\begin{tabular}{cccccccc}
\hline No. & Bak & 5 & 10 & 15 & 20 & 25 & 30 \\
\hline 1 & 1 & $16 \mathrm{~cm}$ & $38 \mathrm{~cm}$ & $50 \mathrm{~cm}$ & $50 \mathrm{~cm}$ & $50 \mathrm{~cm}$ & $50 \mathrm{~cm}$ \\
2 & 2 & $0 \mathrm{~cm}$ & $0 \mathrm{~cm}$ & $2 \mathrm{~cm}$ & $14 \mathrm{~cm}$ & $30 \mathrm{~cm}$ & $45,5 \mathrm{~cm}$ \\
3 & 3 & $0 \mathrm{~cm}$ & $0 \mathrm{~cm}$ & $0 \mathrm{~cm}$ & $0 \mathrm{~cm}$ & $0 \mathrm{~cm}$ & $0 \mathrm{~cm}$ \\
\hline
\end{tabular}

Tabel 3. Debit masukan selama 30 menit pada debit 0,202 liter/detik pada tanah kering

\begin{tabular}{cccc}
\hline No & Bak & $\begin{array}{c}\text { Waktu } \\
\text { (menit) }\end{array}$ & $\begin{array}{c}\text { Debit Terserap } \\
\text { (liter) }\end{array}$ \\
\hline 1 & 1 & 5 & 20.6 \\
2 & 1 & 10 & 26.2 \\
3 & $1 \& 2$ & 15 & 51.8 \\
4 & $1 \& 2$ & 20 & 82,4 \\
5 & $1 \& 2$ & 25 & 103 \\
6 & $1 \& 2$ & 30 & 124.85 \\
\hline
\end{tabular}

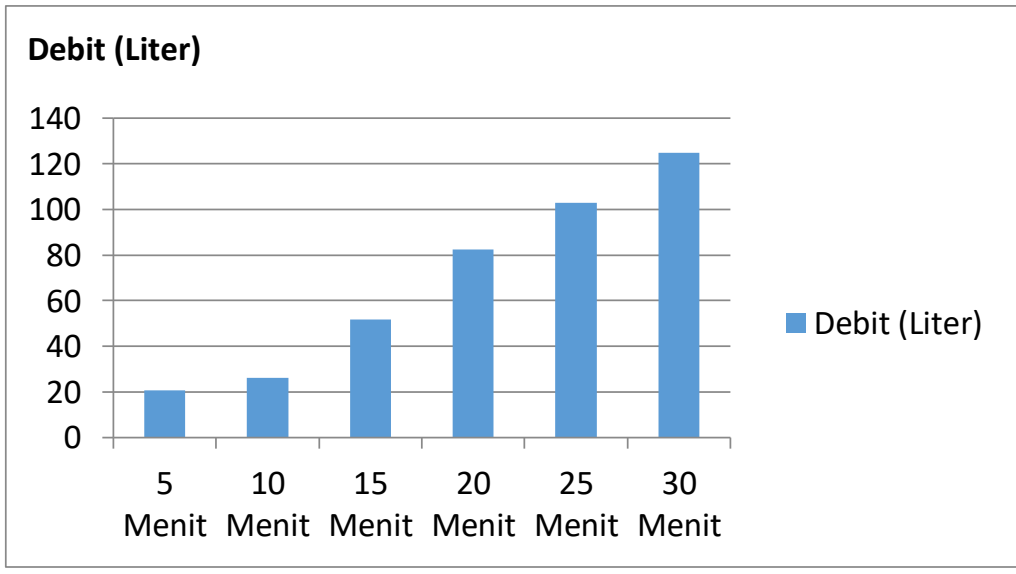


Gambar 4. Grafik debit masukan selama 30 menit pada debit 0,202 liter/detik pada tanah kering

Pada Tabel 2 dan Tabel 3 diatas menunjukkan hasil pengukuran pada area tanah kering dengan debit 0,202 liter/detik didapatkan volume air yang masuk kedalam bak selama 30 menit sebesar 363,6 liter. Volume tertampung sebesar 238,75 liter, volume air yang terserap sebesar 124,85 liter, dan debit limpasan 0 liter/detik.

Langkah yang sama dilakukan terhadap kondisi tanah lembab/basah yang memperoleh data sebagai berikut:

Tabel 4. Debit masuk 0,202 liter/detik pada tanah lembab/basah

\begin{tabular}{|c|c|c|c|c|}
\hline \multirow[t]{2}{*}{ No. } & \multirow[t]{2}{*}{ Debit } & \multicolumn{3}{|c|}{ Interval Waktu } \\
\hline & & Bak 1 & Bak 2 & Bak 3 \\
\hline 1. & 0,202 liter/detik & 00:00:00 & $00: 11: 10$ & $00: 27: 30$ \\
\hline
\end{tabular}

Tabel 5. Tinggi muka air tiap bak selama 30 menit pada debit 0,202 liter/detik pada tanah lembab/basah

\begin{tabular}{cccccccc}
\hline No. & Bak & 5 & 10 & 15 & 20 & 25 & 30 \\
\hline 1 & 1 & $23 \mathrm{~cm}$ & $46 \mathrm{~cm}$ & $50 \mathrm{~cm}$ & $50 \mathrm{~cm}$ & $50 \mathrm{~cm}$ & $50 \mathrm{~cm}$ \\
2 & 2 & $0 \mathrm{~cm}$ & $0 \mathrm{~cm}$ & $12 \mathrm{~cm}$ & $29 \mathrm{~cm}$ & $44,5 \mathrm{~cm}$ & $50 \mathrm{~cm}$ \\
3 & 3 & $0 \mathrm{~cm}$ & $0 \mathrm{~cm}$ & $0 \mathrm{~cm}$ & $0 \mathrm{~cm}$ & $0 \mathrm{~cm}$ & $0 \mathrm{~cm}$ \\
\hline
\end{tabular}

Tabel 6. Debit masukan selama 30 menit pada debit 0,202 liter/detik pada tanah lembab/basah

\begin{tabular}{cccc}
\hline No & Bak & $\begin{array}{c}\text { Waktu } \\
\text { (menit) }\end{array}$ & $\begin{array}{c}\text { Debit Terserap } \\
\text { (liter) }\end{array}$ \\
\hline 1 & 1 & 5 & 3.1 \\
2 & 1 & 10 & 6.2 \\
3 & $1 \& 2$ & 15 & 26.8 \\
4 & $1 \& 2$ & 20 & 44.9 \\
5 & $1 \& 2$ & 25 & 66.75 \\
6 & $1 \& 2$ & 30 & 113.6 \\
\hline
\end{tabular}

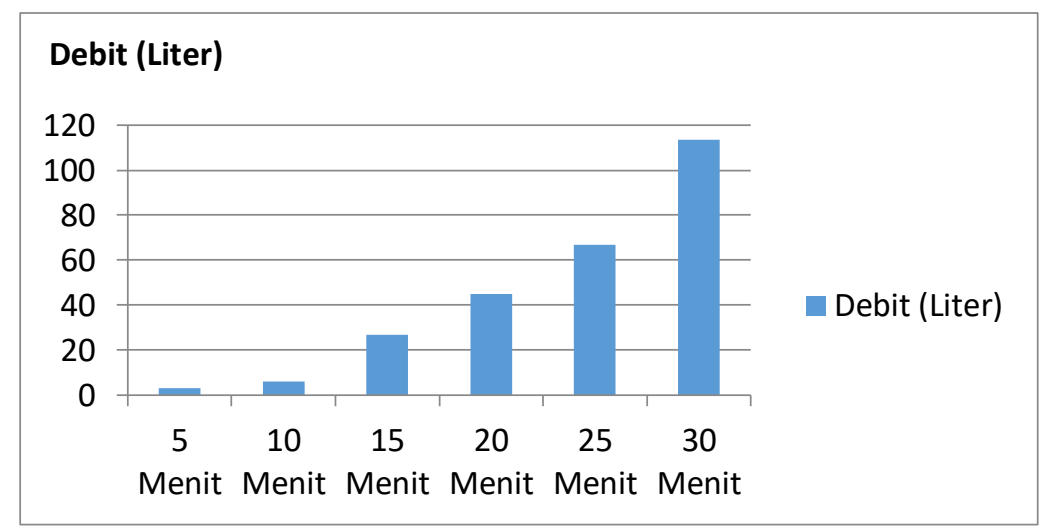

Gambar 5. Grafik debit masukan selama 30 menit pada debit 0,202 liter/detik pada tanah lembab/basah 
Pada Tabel 5 dan Tabel 6 diatas menunjukkan hasil pengukuran pada area tanah lembab/basah dengan debit 0,202 liter/detik didapatkan volume air yang masuk kedalam bak selama 30 menit sebesar 363,6 liter, volume air tertampung sebesar 250 liter, volume air yang terserap sebesar 133,6 liter, dan debit limpasan 0 liter/detik.

\section{Running Debit 0,3654 liter/detik}

Percobaan pada tanah kering dengan debit 0.3654 liter/detik dilakukan selang 2-3 hari dari masa percobaan sebelumnya guna mendapatkan kondisi tanah yang diharapkan. Percobaan dilakukan dengan mengalirkan air kedalam bak resapan-1. Lama pengairan selama 30 menit dengan mencatat ketinggian muka air pada bak resapan setiap 5 menit serta melakukan pencatatan waktu aliran air mulai masuk pada setiap bak resapan. Selanjutnya didapat data sebagai berikut:

Tabel 7. Debit masuk 0,3654 liter/detik pada tanah kering

\begin{tabular}{|c|c|c|c|c|}
\hline \multirow[t]{2}{*}{ No. } & \multirow[t]{2}{*}{ Debit } & \multicolumn{3}{|c|}{ Interval Waktu } \\
\hline & & Bak 1 & Bak 2 & Bak 3 \\
\hline 1. & 0,3654 liter/detik & 00:00:00 & $00: 08: 43$ & $00: 21: 10$ \\
\hline
\end{tabular}

Tabel 8. Tinggi muka air tiap bak selama 30 menit pada debit 0,3654 liter/detik pada tanah kering

\begin{tabular}{cccccccc}
\hline No. & Bak & 5 & 10 & 15 & 20 & 25 & 30 \\
\hline 1 & 1 & $28 \mathrm{~cm}$ & $50 \mathrm{~cm}$ & $50 \mathrm{~cm}$ & $50 \mathrm{~cm}$ & $50 \mathrm{~cm}$ & $50 \mathrm{~cm}$ \\
2 & 2 & $0 \mathrm{~cm}$ & $0 \mathrm{~cm}$ & $22 \mathrm{~cm}$ & $45 \mathrm{~cm}$ & $50 \mathrm{~cm}$ & $50 \mathrm{~cm}$ \\
3 & 3 & $0 \mathrm{~cm}$ & $0 \mathrm{~cm}$ & $0 \mathrm{~cm}$ & $0 \mathrm{~cm}$ & $0 \mathrm{~cm}$ & $2 \mathrm{~cm}$ \\
\hline
\end{tabular}

Tabel 9. Debit masukan selama 30 menit pada debit 0,3654 liter/detik pada tanah kering

\begin{tabular}{cccc}
\hline No & Bak & $\begin{array}{c}\text { Waktu } \\
\text { (menit) }\end{array}$ & $\begin{array}{c}\text { Debit Terserap } \\
\text { (liter) }\end{array}$ \\
\hline 1 & 1 & 5 & 39.62 \\
2 & 1 & 10 & 94.25 \\
3 & $1 \& 2$ & 15 & 148.86 \\
4 & $1 \& 2$ & 20 & 200.98 \\
5 & $1 \& 2$ & 25 & 298.1 \\
6 & $1,2 \& 3$ & 30 & 402.72 \\
\hline
\end{tabular}

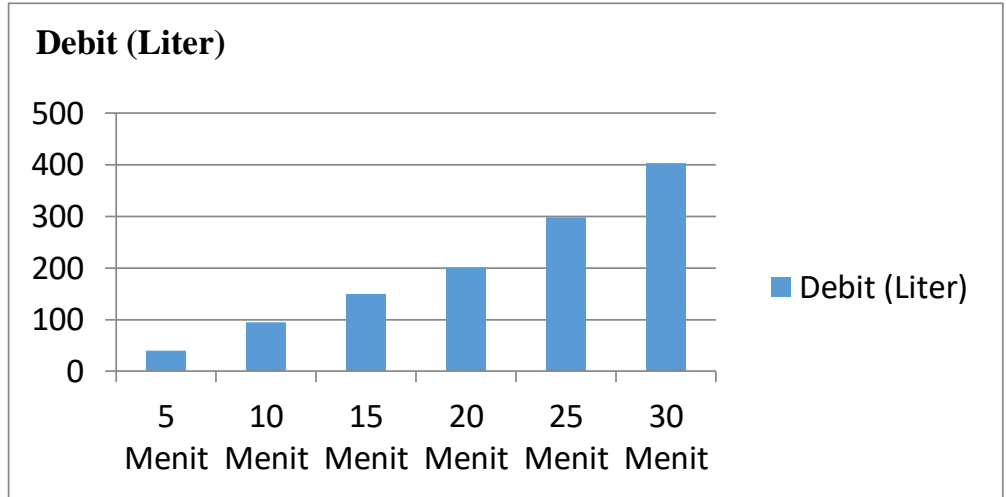

Gambar 6. Grafik debit masukan selama 30 menit pada debit 0,3654 liter/detik pada tanah kering 
Pada Tabel 8 dan Tabel 9 diatas menunjukkan hasil pengukuran pada area tanah kering dengan debit 0,3654 liter/detik didapatkan volume air yang masuk kedalam bak selama 30 menit sebesar 657.72 liter. Volume tertampung sebesar 255 liter, volume air yang terserap sebesar 402.72 liter, dan debit limpasan 0 liter/detik.

Langkah yang sama dilakukan terhadap kondisi tanah lembab/basah yang memperoleh data sebagai berikut:

Tabel 10. Debit masuk 0,3654 liter/detik pada tanah lembab/basah

\begin{tabular}{|c|c|c|c|c|}
\hline \multirow[t]{2}{*}{ No. } & \multirow[t]{2}{*}{ Debit } & \multicolumn{3}{|c|}{ Interval Waktu } \\
\hline & & Bak 1 & Bak 2 & Bak 3 \\
\hline 1. & 0,3654 liter/detik & 00:00:00 & $00: 06: 25$ & $00: 14: 56$ \\
\hline
\end{tabular}

Tabel 11. Tinggi muka air tiap bak selama 30 menit pada debit 0,3654 liter/detik pada tanah lembab/basah

\begin{tabular}{cccccccc}
\hline No. & Bak & \multicolumn{5}{c}{ Waktu (menit) } \\
& & 5 & 10 & 15 & 20 & 25 & 30 \\
\hline 1 & 1 & $40 \mathrm{~cm}$ & $50 \mathrm{~cm}$ & $50 \mathrm{~cm}$ & $50 \mathrm{~cm}$ & $50 \mathrm{~cm}$ & $50 \mathrm{~cm}$ \\
2 & 2 & $0 \mathrm{~cm}$ & $22 \mathrm{~cm}$ & $50 \mathrm{~cm}$ & $50 \mathrm{~cm}$ & $50 \mathrm{~cm}$ & $50 \mathrm{~cm}$ \\
3 & 3 & $0 \mathrm{~cm}$ & $0 \mathrm{~cm}$ & $0 \mathrm{~cm}$ & $12 \mathrm{~cm}$ & $23,5 \mathrm{~cm}$ & $35,5 \mathrm{~cm}$ \\
\hline
\end{tabular}

Tabel 12. Debit masukan selama 30 menit pada debit 0,3654 liter/detik tanah lembab/basah

\begin{tabular}{cccc}
\hline No & Bak & $\begin{array}{c}\text { Waktu } \\
\text { (menit) }\end{array}$ & $\begin{array}{c}\text { Debit Terserap } \\
\text { (liter) }\end{array}$ \\
\hline 1 & 1 & 5 & 9.62 \\
2 & 1 & 10 & 39.24 \\
3 & $1 \& 2$ & 15 & 78.86 \\
4 & $1,2 \& 3$ & 20 & 158.48 \\
5 & $1,2 \& 3$ & 25 & 239.35 \\
6 & $1,2 \& 3$ & 30 & 318.97 \\
\hline
\end{tabular}

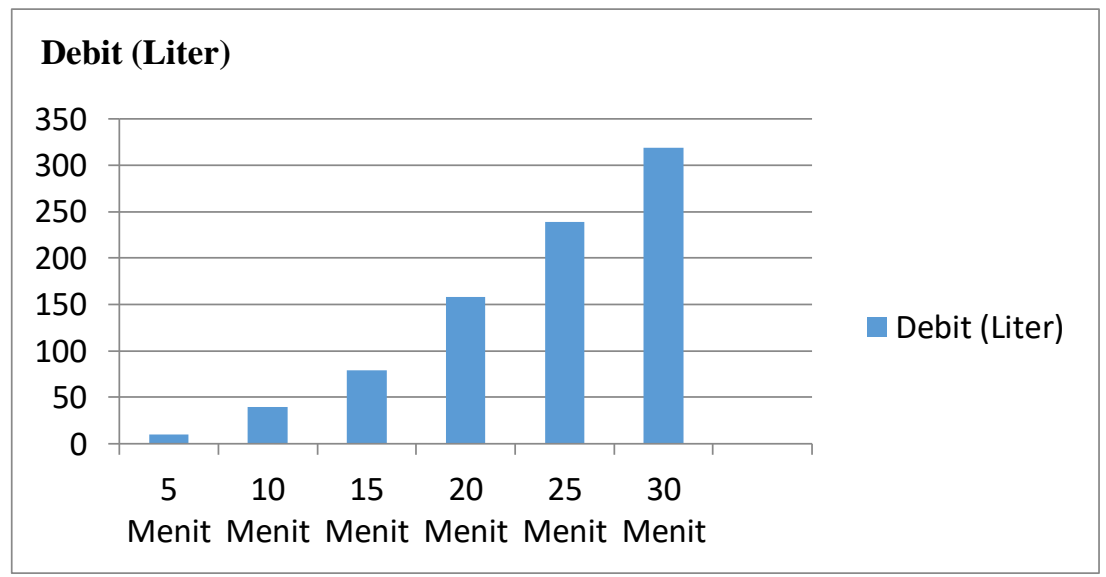

Gambar 7. Grafik debit masukan selama 30 menit pada debit 0,3654 liter/detik pada tanah lembab/basah

Pada Tabel 11 dan Tabel 12 diatas menunjukkan hasil pengukuran pada area tanah lembab/basah dengan debit 0,3654 liter/detik didapatkan volume air yang masuk kedalam bak selama 30 menit sebesar 657.72 liter, volume tertampung sebesar 338,75 liter, volume air yang terserap sebesar 378,97 liter, dan debit limpasan 0 liter/detik. 


\section{Running Debit 0,8178 liter/detik}

Percobaan pada tanah kering dengan debit 0,8178 liter/detik dilakukan selang 2-3 hari dari masa percobaan sebelumnya guna mendapatkan kondisi tanah yang diharapkan. Percobaan dilakukan dengan mengalirkan air kedalam bak resapan-1. Lama pengairan selama 30 menit dengan mencatat ketinggian muka air pada bak resapan setiap 5 menit serta melakukan pencatatan waktu aliran air mulai masuk pada setiap bak resapan. Selanjutnya didapat data sebagai berikut:

Tabel 13. Debit masuk 0,8178 liter/detik pada tanah kering

\begin{tabular}{|c|c|c|c|c|}
\hline \multirow[t]{2}{*}{ No. } & \multirow[t]{2}{*}{ Debit } & \multicolumn{3}{|c|}{ Interval Waktu } \\
\hline & & Bak 1 & Bak 2 & Bak 3 \\
\hline 1. & 0,8178 liter/detik & 00:00:00 & 00:03:10 & $00: 07: 28$ \\
\hline
\end{tabular}

Tabel 14. Tinggi muka air tiap bak selama 30 menit pada debit 0,8178 liter/detik pada tanah kering

\begin{tabular}{cccccccc}
\hline No. & Bak & 5 & 10 & 15 & 20 & 25 & 30 \\
\hline 1 & 1 & $50 \mathrm{~cm}$ & $50 \mathrm{~cm}$ & $50 \mathrm{~cm}$ & $50 \mathrm{~cm}$ & $50 \mathrm{~cm}$ & $50 \mathrm{~cm}$ \\
2 & 2 & $0 \mathrm{~cm}$ & $17 \mathrm{~cm}$ & $50 \mathrm{~cm}$ & $50 \mathrm{~cm}$ & $50 \mathrm{~cm}$ & $50 \mathrm{~cm}$ \\
3 & 3 & $0 \mathrm{~cm}$ & $0 \mathrm{~cm}$ & $3 \mathrm{~cm}$ & $21 \mathrm{~cm}$ & $39,5 \mathrm{~cm}$ & $50 \mathrm{~cm}$ \\
\hline
\end{tabular}

Tabel 15. Debit masukan selama 30 menit pada debit 0,8178 liter/detik pada tanah kering

\begin{tabular}{cccc}
\hline No & Bak & $\begin{array}{c}\text { Waktu } \\
\text { (menit) }\end{array}$ & $\begin{array}{c}\text { Debit Terserap } \\
\text { (liter) }\end{array}$ \\
\hline 1 & 1 & 5 & 120.34 \\
2 & $1 \& 2$ & 10 & 323.18 \\
3 & $1,2 \& 3$ & 15 & 478.52 \\
4 & $1,2 \& 3$ & 20 & 678.86 \\
5 & $1,2 \& 3$ & 25 & 877.95 \\
6 & $1,2 \& 3$ & 30 & 922.073 \\
\hline
\end{tabular}

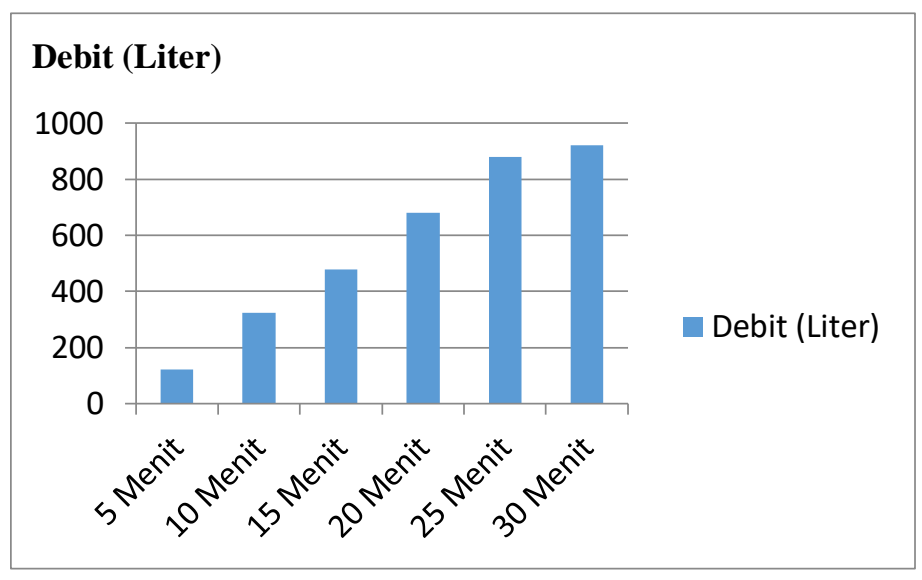

Gambar 8. Grafik debit masukan selama 30 menit pada debit 0,8178 liter/detik pada tanah kering 
Pada Tabel 14 dan Tabel 15 diatas menunjukkan hasil pengukuran pada area tanah kering dengan debit 0,8178 liter/detik didapatkan volume air yang masuk kedalam bak selama 30 menit sebesar 1297,0728 liter. Volume tertampung sebesar 375 liter, volume air yang terserap sebesar 922,073 liter, dan debit limpasan 174,97 liter.

Langkah yang sama dilakukan terhadap kondisi tanah lembab/basah yang memperoleh data sebagai berikut:

Tabel 16. Debit masuk 0,8178 liter/detik pada tanah lembab/basah

\begin{tabular}{|c|c|c|c|c|}
\hline \multirow[t]{2}{*}{ No. } & \multirow[t]{2}{*}{ Debit } & \multicolumn{3}{|c|}{ Interval Waktu } \\
\hline & & Bak 1 & Bak 2 & Bak 3 \\
\hline 1. & 0,8178 liter/detik & 00:00:00 & $00: 03: 14$ & 00:06:37 \\
\hline
\end{tabular}

Tabel 17. Tinggi muka air tiap bak selama 30 menit pada debit 0,8178 liter/detik pada tanah lembab/basah

\begin{tabular}{cccccccc}
\hline No. & Bak & \multicolumn{5}{c}{ Waktu (menit) } \\
& & 5 & 10 & 15 & 20 & 25 & 30 \\
\hline 1 & 1 & $50 \mathrm{~cm}$ & $50 \mathrm{~cm}$ & $50 \mathrm{~cm}$ & $50 \mathrm{~cm}$ & $50 \mathrm{~cm}$ & $50 \mathrm{~cm}$ \\
2 & 2 & $27 \mathrm{~cm}$ & $50 \mathrm{~cm}$ & $50 \mathrm{~cm}$ & $50 \mathrm{~cm}$ & $50 \mathrm{~cm}$ & $50 \mathrm{~cm}$ \\
3 & 3 & $0 \mathrm{~cm}$ & $17 \mathrm{~cm}$ & $50 \mathrm{~cm}$ & $50 \mathrm{~cm}$ & $50 \mathrm{~cm}$ & $50 \mathrm{~cm}$ \\
\hline
\end{tabular}

Tabel 18. Debit masukan selama 30 menit pada debit 0,8178 liter/detik pada tanah kering

\begin{tabular}{cccc}
\hline No & Bak & $\begin{array}{c}\text { Waktu } \\
\text { (menit) }\end{array}$ & $\begin{array}{c}\text { Debit Terserap } \\
\text { (liter) }\end{array}$ \\
\hline 1 & $1 \& 2$ & 5 & 127.84 \\
2 & $1,2 \& 3$ & 10 & 198.18 \\
3 & $1,2 \& 3$ & 15 & 354.036 \\
4 & $1,2 \& 3$ & 20 & 392.65 \\
5 & $1,2 \& 3$ & 25 & 428.47 \\
6 & $1,2 \& 3$ & 30 & 464.3 \\
\hline
\end{tabular}

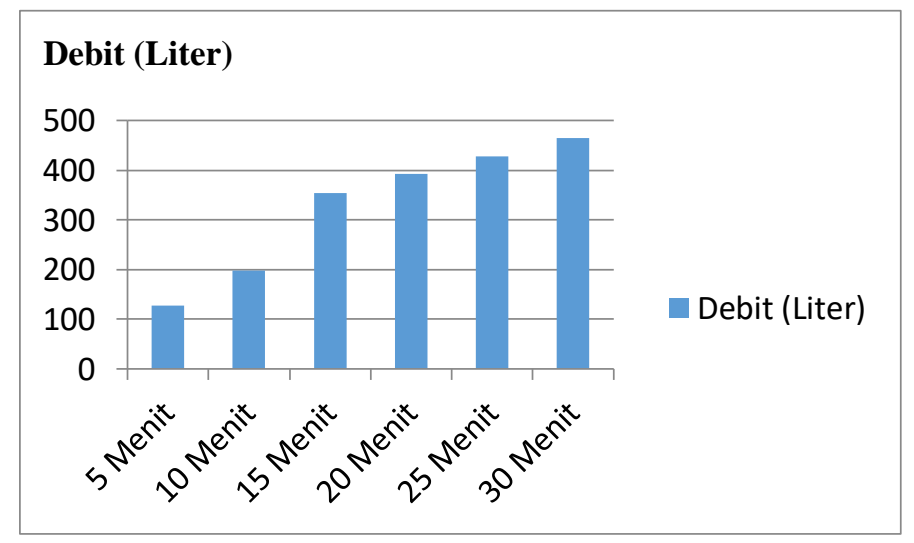

Gambar 9. Grafik debit masukan selama 30 menit pada debit 0,8178 liter/detik pada tanah lembab/basah

Pada Tabel 17 dan Tabel 18 diatas menunjukkan hasil pengukuran pada area tanah lembab/basah dengan debit 0,8178 liter/detik didapatkan volume air yang masuk kedalam bak selama 30 menit sebesar 839,296 liter, volume tertampung sebesar 375 liter, volume air yang terserap sebesar 464,296 liter, dan debit limpasan 632,772 liter.

\section{Analisa Reduksi Limpasan Permukaan}

Tabel 19 dibawah ini menunjukkan hasil analisa reduksi limpasan permukaan pada setiap penelitian. 
Tabel 19. Hasil analisa persentase reduksi pada tiap percobaan

\begin{tabular}{ccccc}
\hline No & Q masuk (liter/detik) & Kondisi Tanah & Q keluar (liter/detik) & Persentase Reduksi(\%) \\
\hline 1 & 0,202 & Kering & 0 & 100 \\
2 & 0,202 & Basah/Lembab & 0 & 100 \\
3 & 0,3654 & Kering & 0 & 100 \\
4 & 0,3654 & Basah/Lembab & 0 & 100 \\
5 & 0,8178 & Kering & 0,1279 & 84,36 \\
6 & 0,8178 & Basah/Lembab & 0,35154 & 57,019 \\
\hline
\end{tabular}

\section{SIMPULAN}

Berdasarkan hasil pengolahan data dapat disimpulkan sebagai berikut :

1. Persentase bak resapan dalam mereduksi debit limpasan pada saat kondisi tanah kering sebesar $94,786 \%$.

2. Persentase bak resapan dalam mereduksi debit limpasan pada saat kondisi tanah lembab/basah sebesar $85.673 \%$.

3. Jumlah volume tertampung pada tiap bak resapan berpengaruh pada kecepatan terserapnya air kedalam tanah dalam segala kondisi. Semakin banyak volume yang tertampung pada tiap bak maka makin besar penyerapan yang terjadi pada tiap bak.

4. Jarak antara tiap bak resapan sangat berpengaruh terhadap besar reduksi limpasan permukaan. Semakin jauh jarak pisah antara bak resapan maka reduksi limpasan juga semakin besar

5. Pada kondisi tanah jenuh air yang meresap kecil. Hal ini sesuai dengan koefisien permeabilitas tanah diarea penelitian sebesar $3,1 \times 10^{-7}$ dan $4,2 \times 10^{-7} \mathrm{~cm} /$ detik yang didapatkan dari uji tanah di Laboraturium Alaska Surakarta.

\section{SARAN}

Setelah mengevaluasi hasil-hasil penelitian yang telah dilakukan, terdapat beberapa saran sebagai berikut :

1. Melakukan penelitian dengan menggunakan air hujan sebagai debit masukan.

2. Kondisi tanah kering diperoleh pada saat musim kemarau.

3. Kondisi tanah lembab/basah diperoleh pada saat musim hujan.

4. Melakukan penelitian dengan menggunakan dengan bentuk tabung.

5. Melakukan percobaan dengan berbagai ukuran dimensi yang berbeda untuk mendapatkan dimensi yang tepat.

\section{DAFTAR PUSTAKA}

\section{DAFTAR PUSTAKA}

Hidayati Kun Yulia, 2009. Evaluasi Pengambilan Air Tanah Surakarta dalam Darsawarsa Tahun 1997. Tesis. Universitas Sebelas Maret Surakarta.

Keputusan Menteri Dalam Negeri. 1999. Nomor: 47. Tentang Pedoman Penilaian Kinerja Perusahaan Daerah Air Minum.

Kusnaedi, 2011. Sumur Resapan Untuk Pemukiman dan Pedesaan. Depok: Penebar Swadaya.

Peraturan Menteri Negara Lingkungan Hidup. 2009. Nomor: 12. Tentang Air Hujan.

Talakua Silwanus Matheus, 2016. Degradasi Lahan Metode Analisis dan Aplikasinya Dalam Penggunaan Lahan.Yogyakarta: Plantaxia.

Tri Yayuk Susana, 2016. Analisis Pemafaatan Air Hujan dengan Menggunakan Cistern sebagai Alternatif Sumber Daya Air Pertamanan pada Gedung Perkantoran Bank Indonesia. Skripsi. Fakultas Teknik Universitas 
Indonesia.

Wahyuningtyas Ayu dkk, 2011. Strategi Penerapan Sumur Resapan Sebagai Teknologi Ekodrainase di Kota Malang. (Studi Kasus Sub DAS Metro). Jurnal. Universitas Brawijaya Malang. 